\title{
Tuberculosis, non-compliance and detention for the public health
}

Richard Coker Consultant Physician, St Mary's Hospital, London

Coercion, the act of compelling someone to do something by the use of power, intimidation, or threats, has been deemed a necessary weapon in the public health armamentarium since before public health fell under the remit of physicians and out of the grip of "sanitarians" and civil engineers. This article examines the ethics of detention in the pursuit of public health and uses a contemporary example, detention of poorly compliant individuals with tuberculosis, to highlight the moral dilemmas posed, and examine whether recently proposed approaches are just. In particular I focus upon the public health response to noninfectious individuals who fail to comply with treatment (and who, therefore, may be at risk of relapsing and becoming infectious). Our response to them helps clarify contemporary attitudes to recalcitrant, often marginalised, individuals who pose an uncertain threat.

Globally tuberculosis control is failing. The World Health Organisation (WHO) recently called this public health threat a global emergency. ${ }^{1}$ Transmission occurs through often casual contact from individuals who have pulmonary disease. Although there is much that is uncertain regarding the infectiousness of this ancient disease, we do know that those who are smear-positive, that is who have organisms of Mycobacterium tuberculosis visible in stained respiratory secretions, are considerably more infectious than those who do not. ${ }^{23}$ Compliance with effective treatment rapidly (within a couple of weeks) makes previously infectious patients noninfectious. Standard treatment for fully drugsensitive tuberculosis usually lasts for six months. Erratic adherence to chemotherapy, however, may result in relapse and the development of drugresistant disease which is considerably more difficult to treat.

In the 1980s and early 1990s New York City witnessed an epidemic of tuberculosis and, of particular concern, a marked increase in drugresistant and multidrug-resistant strains. In the early 1990 s the threat of a virtually untreatable, casually communicable, infectious disease was perceived with alarm in New York as a realistic possibility. It was suggested at the time that persistently poorly compliant "delinquent patients are the core of New York City's TB problem". ${ }^{4}$

To address the problem of poor compliance, in addition to a variety of other measures taken, the local public health regulations were amended. ${ }^{5}$ This change in "police powers" gave the commissioner of health, the mayor's representative, the authority to detain for prolonged periods individuals who failed, or could be expected to fail, to comply with treatment irrespective of whether they were infectious or not. This measure represented a substantial increase in the state's authority. No longer was detention to be based upon an assessment of the threat posed to public health - an assessment of compliance with treatment would suffice. Since 1993 more than 200 non-infectious individuals have been held in the main detention centre, at Goldwater Memorial Hospital on Roosevelt Island, most for prolonged periods, and some for more than two years. ${ }^{6}$ Following New York's lead, the Centers for Disease Control and prevention issued national guidelines advocating similar measures be adopted across all states. ${ }^{7}$ Many in the US have followed this guidance and in Britain prolonged detention of tuberculous patients is occasionally advocated despite uncertainties over the legal soundness of this approach. ${ }^{78}$

Specifically, the 1993 amendments to the New York City health codes allow detention under two important scenarios. Firstly, even as the potential threat posed by tuberculous individuals dwindles to almost completely nil as a treatment course nears completion, an individual may still be detained until the treatment course is completed. Secondly, in New York, detention may be authorised even when less restrictive alternatives have 
not been attempted (such as supervised community support and directly observed therapy).

Clearly coercion is right and necessary on occasion where the public health is threatened. From a utilitarian perspective coercion may be just in cases of dangerous, irresponsible individuals with either a communicable disease or mental illness. This utilitarian ethic has a pragmatic character which is appealing. The utility gain in such cases appears to be greater than the utility loss across society. If this is clearly the case then the coercive action, for example detention of potentially infectious tuberculous individuals or potentially dangerous mentally ill patients, is moral. Indeed, it could be argued, it would be ethically wrong not to use coercive measures in such circumstances if alternative, less restrictive, approaches had failed. This is, broadly, the public health argument which is currently holding sway. But there are two issues which need exploring, both highlighted by the public health code amendments which took place in New York.

\section{Risk assessment}

The first is, what if the utility gain is less than the utility loss across society, if the threat posed to society is small, or, even more problematic, unquantifiable? Typically the argument for the common good over individual rights is presented in the form of risk assessment. ${ }^{9}$ Historically the explicit use of coercion, and in particular the use of detention, has hinged upon notions of risk; not only the probability of any given event occurring, but also the magnitude of threat posed. If the threat posed is small, if the utility gain is less than the loss across society, then, from a utilitarian perspective, the use of coercion is unjust. In the case of non-infectious non-compliant (HIVseronegative) individuals, the threat posed probably is small and dwindles with time as treatment continues. But in the case of HIV-seropositive cases the risk of relapse to an infectious state is substantially higher. Should, therefore, those who are non-compliant and HIV-seropositive face detention, whereas those who are HIVseronegative be left unconstrained? Or does this approach discriminate unduly against certain classes of patient? Alternatively, is there a risk threshold beyond which one may be detained? For example, given that the risk of relapse is higher if compliance with treatment ceases after two months of treatment compared with, say, five months (where, in most cases it is probably very small indeed), should those who fail to comply after two months face the prospect of detention if they fail to comply, whereas those who do so only after five months remain at liberty? And what about the magnitude of the threat? The threat posed from drug-resistant and multidrug-resistant tuberculosis is far greater than that from fully sensitive strains. Yet predicting who will develop multidrug-resistant tuberculosis is almost impossible. In examining these notions of risk one is forced to question issues relating to utility, about how one measures the burden of risk, and utility gains and losses. Objective evidence to support decisions is largely lacking.

Because much of what is accepted dogmatically with regard to the transmissibility of tuberculosis is, in fact, dogma and myth, ${ }^{2}$ and because tuberculosis frequently affects those living on the margins of society (the homeless, immigrants, drug users) social tensions are highlighted. Policy responses illuminate social and political mores of the moment. They illustrate the degree to which society is prepared, or rather unprepared, to be burdened by uncertain threats emanating from often marginalised populations. How policymakers respond reflects the choices of society. In Britain detention of individuals with tuberculosis for prolonged periods (up to six months) is being countenanced whilst at the same time there are insufficient community-based programmes offering compliance incentives, and alternative methods to enhance treatment compliance are inadequately resourced. ${ }^{81011}$ Similar criticisms have been levelled at community-based care for the potentially dangerous mentally ill. ${ }^{12}$

In their book, Tragic Choices, Guido Calabresi and Philip Bobbitt, suggest that "By making the result[of a tragic choice, for example detention rather than community-based support] seem necessary, unavoidable, rather than chosen, [policymakers] attempt to convert what is tragically chosen into what is merely a fatal misfortune". ${ }^{13}$ That is, detention of "recalcitrant" individuals appears to be the only option. A charade is promoted by this approach which suggests that, firstly, the seeds which nurtured such "dangerous" non-compliant behaviour (poverty, homelessness, social inequities, social exclusion) are not open to remedy, and secondly, that there is no alternative approach to controlling such individuals who now pose a threat (albeit of uncertain magnitude). Consequently incentives and "enablers" to change destructive behaviour and encourage compliance are given insufficient support. If society fails to recognise, or lend sufficient weight, to alternative approaches it avoids having to make morally difficult decisions. We must ask, therefore, is the use of coercion simply a charade of policy-making, or is it an explicit unwillingness to provide an adequate framework of care within the community for those in need in order to enable them to remain at 
liberty and minimise the threat they pose to others? Clarity in policy choices makes any charade less sustainable.

The second issue raised is that of detention before alternative, less restrictive, approaches have been attempted. This approach suggests that experts are able to judge when the threat of detention will not be sufficient to encourage conformity. Yet just as history (and behavioural psychologists) have taught us that experts frequently mis-judge the magnitude of risk, ${ }^{14}$ experts are also poor at predicting behaviour in relation to treatment compliance. ${ }^{15}$ Furthermore, in addition to uncertainties surrounding the prediction of behaviour, there is a moral dilemma which Thomas Babington Macauley illustrated when he wrote that "many politicians of our time are in the habit of laying it down as a self-evident proposition that no people are to be free till they are fit to use their freedom. The maxim is worthy of the fool in the old story who resolved not to go into the water till he had learned to swim. If men are to wait for liberty till they become wise and good, they may indeed wait forever" ${ }^{16}$ These sentiments continue to hold true today.

The recent change in emphasis in the balance between civil liberties and public health protection is not unique to the US, nor to communicable diseases. In the UK, for example, in the mental health sphere the current government blames the failure of community care for the mentally ill on, in addition to underfunding, inadequate services, and problems recruiting and retaining staff, an outdated legal framework, and has called for "assertive outreach" underpinned by the threat of detention "to ensure compliance with appropriate treatment". ${ }^{17}$ Indeed the previous government considered similar measures in the early 1990 s. $^{18}$

This shift in the balance between individual civil liberties and the protection of the public health represents a significant departure from the liberal stance of the 1960s and 1970s which gave patient autonomy greater prominence than the doctor's beneficence and non-maleficence. Yet where harm to others arises from any individuals' actions (or in the case of tuberculosis, failure to take action) constraints on behaviour, restrictions on autonomy, may be necessary. But we should remember that signal events, such as the stabbing of Jonathan Zito by Chistopher Clunis, a paranoid schizophrenic, in London, and the death from multidrug-resistant tuberculosis of a prison guard in New York, amplify both the public's and experts' perception of public health threat. We should strive to be objective in our assessment of risk, and the gains and losses following intervention. Ultimately the approach we take to individuals with communicable diseases who are noninfectious but potentially pose a public health threat reflects upon society itself, the burden we are prepared to bear in support of patient autonomy, our perceptions of those living on the margins, and our commitment to supporting a network of community care for our most vulnerable citizens.

Richard Coker, MD, FRCP, is a Consultant Physician at St Mary's Hospital, London.

\section{References}

1 World Health Organisation. TB - a global emergency. Geneva, 1994: World Health Organisation, 1994.

2 Sepkowitz KA. How contagious is tuberculosis? Clinical Infectious Diseases 1996;23:954-62.

3 Nunn P, Mungai M, Nyamwaya J, Gicheha C, Brindle RJ, Dunn DT. The effect of human immunodeficiency virus type-1 on the infectiousness of tuberculosis. Tubercle and Lung Disease 1994;75:25-32.

4 Brudney K, Dobkin J. A tale of two cities: tuberculosis control in Managua and New York City. Seminars in Respiratory

5 New York City, NY. Health Code 11.47 (1993).

6 Coker RJ. Carrots, sticks and tuberculosis. Thorax 1999;54:95-6.

7 Centers for Disease Control. Tuberculosis control laws United States, 1993. Morbidity and Mortality Weekly Report

8 Coker RJ. Public health, civil liberties and tuberculosis. British Medical fournal 1999;318:1434-5.

9 Bedical fournal 1999;318:1434-5. Banta HD. What is health care? In: Kovner AR, ed. Heath
delivery in the United States. New York: Springer, 1990.

10 Hayward A. Tuberculosis control in London: the need for change. London: NHS, 1998

11 Gordon A. TB refugee 'must be held in hospital'. The Mail on Sunday 1998 Aug 30:15.

12 Marshall M. Modernising mental health services: time to define the boundaries of psychiatric care. British Medical fournal 1999;318:3-4

13 Calabresi G, Bobbitt P. Tragic choices. New York: W W Norton \& Company, 1978

14 Kahneman D, Tversky A. Subjective probability. In: Kahneman D, Tversky A, Slovic P, eds. Fudgement under uncertainty: heuristics and biases. Cambridge: Cambridge University Press, 1981.

15 Sumartojo E. When tuberculosis treatment fails: a social behavioural account of patient adherence. American Review of behavioural account of patient adherence

16 Macaulay TB. Review 1843 Vol 1. Edinburgh: Milton

16 Macaulay TB. Review 1843 Vol 1. Edinburgh: Milton. Department of Health. Modernising
London: Department of Health, 1998.

18 Hall C. Mental health review follows attack by lion. The Independent 1993 Jan 4:27. 